\title{
Longitudinal Market Valuation of Unexpectedly Increased R\&D Expenditure with the Real Option Logic
}

\author{
Hyeri Jung ${ }^{1}$, Jaeho Lee ${ }^{2 *}$ \\ ${ }^{1}$ Technology Innovation Management Graduate Program, Pohang University of Science and Technology, Pohang, South Korea \\ ${ }^{2}$ Department of International Business and Trade, Kyung Hee University, Seoul, South Korea \\ Email: ${ }^{\star}$ jaeholee@khu.ac.kr
}

How to cite this paper: Jung, H., \& Lee, J. (2021). Longitudinal Market Valuation of Unexpectedly Increased R\&D Expenditure with the Real Option Logic. Open Journal of Business and Management, 9, 2530-2547. https://doi.org/10.4236/ojbm.2021.95139

Received: July 15, 2021

Accepted: September 25, 2021

Published: September 28, 2021

Copyright (๑) 2021 by author(s) and Scientific Research Publishing Inc. This work is licensed under the Creative Commons Attribution International License (CC BY 4.0).

http://creativecommons.org/licenses/by/4.0/

\begin{abstract}
This paper examines how the real option value of $R \& D$ expenditure in financial market changes as time proceeds. It examines the relations between the $\mathrm{R} \& \mathrm{D}$ capital and the firm value for 4 years from the time a firm increases its $R \& D$ expenditure unexpectedly. The results show that the financial market evaluates the unexpected increased $R \& D$ with real option logic. We find that the financial market takes account of the market uncertainty and the technology uncertainty of R\&D for the valuation of firms. These effects appear significantly right after the R\&D capital increases unexpectedly. However, the lasting period of them is shorter than 1 year. The operational performance doesn't have any relation with the firm value in our analysis.
\end{abstract}

\section{Keywords}

R\&D Valuation, Real Option, Technology Uncertainty

\section{Introduction}

Traditionally, the discounted cash flow (DCF) method has been used to evaluate $\mathrm{R} \& \mathrm{D}$ projects. The DCF method is defined as a valuation tool to discount expected future cash flow by firm's risk adjusted rate. When the companies value the $R \& D$ projects, the value is affected by many internal and external factors such as market and technology uncertainties around the companies. Also, in reality, managers can choose several strategic options for the projects such as "delaying", "expanding", or "contracting". However, the DCF method has limitation in consideration of the strategic flexibility of projects. The discounted cash flow method may not be accurate for valuing long term and risky $R \& D$ projects. 
Therefore, real option has been studied as a complementary valuation tool of $\mathrm{R} \& \mathrm{D}$ investment. The real option value consists of intrinsic value and premium. The intrinsic value of the $R \& D$ projects is the net present value of the $R \& D$ projects. The premium is an option value of the $R \& D$ projects, that is, a function of $R \& D$ payoff volatility. This indicates that the premium decreases to zero at the expiration date when the $\mathrm{R} \& \mathrm{D}$ projects are completed. Also, most of intangible $\mathrm{R} \& \mathrm{D}$ assets don't trade among the firms. This implies that the firms can make a loss from the failure of $R \& D$ project unless the $R \& D$ projects improve operating performance.

This paper examines how the financial market evaluates a firm when it increases R\&D capitals unexpectedly. The unexpectedly increased R\&D capital gives a signal to the financial market that the firm launches unordinary and riskier R\&D project. We expect that the financial market evaluates the unexpectedly increased R\&D capital with real option rather than DCF. And the real option value of $R \& D$ expenditure in the financial market changes as time goes by. This paper examines the relations between the R\&D capital and the firm value for four years from the time a firm increases its $R \& D$ expenditure unexpectedly. We try to explain the change of the real option value for $R \& D$ expenditure in terms of the market and technological uncertainty.

In this research, we assume that unexpected $R \& D$ expenditures generate market and technology uncertainties and are reflected in the valuation of the firm with the real option logic when they are evaluated in financial markets. In a sense that this research attempts to figure out one of the main factors that affect the valuation of the firms in terms of R\&D expenditures, this paper can be recognized as containing an important content in corporate finance research. In this paper, we find empirical evidence that the financial market takes account of these uncertainties of R\&D, using Korean market and firm data. One of the main contributions of our paper is the empirical evidence that confirms that financial markets evaluate market and technology uncertainties inherent in $R \& D$ investment, in particular, by the logic of real option. A body of research states that R\&D expenditures increase uncertainties for the valuation of the firms; this paper is one of the research that examines the relationship between R\&D capital and firm value. Theoretical logic and empirical evidence from this paper can be generalizable to other financial markets, too. In this way, we add other important empirical findings using Korean market data that other researchers can refer to for their future research in the similar topics. Our empirical analysis focuses on the years of 1999-2008, and does not include more recent updated data for the empirical analysis. However, we argue that it is worthwhile to investigate how the firm value reacted to unexpected $R \& D$ expenditure increases during this time period, when the global and Korean financial markets experienced turbulent and unstable changes with the IT bubble and global financial crisis. In this way, this paper deals with a focused time period and provides a specific insight to the corporate finance research. 
This paper is organized as follows. In Section 2, we review the existing literature. Section 3 presents several hypotheses we formulate. Section 4 describes the data set and discusses the methodology to be used. Section 5 presents the results of empirical analysis. Section 6 concludes.

\section{Existing Research}

\subsection{Factors for Success in R\&D Projects and New Product Innovation}

The R\&D projects and new product development (NPD) are the firm's growth engine to generate future revenue. The firms which have capability to conduct R\&D successfully and develop the NPD can continue to grow. Therefore, many studies attempt to find the success factors of R\&D and NPD. Balachandra and Friar (1997) reviewed the 60 papers in the past 30 years and extracted the universal factors to affect the result of R\&D and NPD. The R\&D success depends on more external factors than internal factors. The technology and market influence the success of R\&D. On the other hand, the NPD success is affected by internal factors than the external factors. The organization affects the success of NPD. This result indicates that the financial market has to consider external factors in order to predict future cash flow which is generated by R\&D.

\subsection{Financial Market Valuation of R\&D}

Many cross sectional research of the firms' $R \& D$ and the financial market valuation have been conducted.

In the short term, the unexpected $R \& D$ increase would relate to the market value of firm. Sougiannis (1994) found that the stock market value was related to the R\&D expenditures. Namara and Fuller (2007) studied investors' short-term response of $1277 \mathrm{R} \& \mathrm{D}$ announcements by 178 listed bio pharmaceutical firms. They found that the abnormal returns take place by the $R \& D$ announcements.

In the long term, the unexpected R\&D increase would raise the market value of the firms by improving operating performance. Bublitz and Ettredge (1989) found that the unexpected $R \& D$ expenditure didn't drive down the firm value after controlling effects of the other revenues and expenses. Sougiannis (1994) concluded that investors placed a high value on $\mathrm{R} \& \mathrm{D}$ investments. On average, a one-dollar increase in $R \& D$ expenditure produces a five dollar increase in the market value. Also, a one-dollar increase in $R \& D$ expenditures leads to a two dollar increase in profit over 7 years. In contrast, Chan, Lakonishok and Sougiannis (2001) found that the R\&D intensity and the subsequent abnormal stock return didn't significantly relate. They stated that the market didn't incorporate the unchanged $R \& D$ intensity into the stock value because the unchanged $R \& D$ expenditure was already reflected in the market value of the firm. The market considered the static $\mathrm{R} \& \mathrm{D}$ expenditure as an ordinary $\mathrm{R} \& \mathrm{D}$. Therefore, there is no reason that the market value of the firm increases. Daniel and Titman (2001) found that the future returns were associated with past intangible returns, but 
not with past tangible returns. Since cash flow generated by the R\&D is not tangible, the R\&D expenditure is categorized as the intangible information. Han and Manry (2004) found the R\&D expenditure was positively associated with stock price. Eberhart, Maxwell and Siddique (2004) studied whether the unexpected $\mathrm{R} \& \mathrm{D}$ increase would result in the long term abnormal stock returns and operating performance. They found that the significantly positive abnormal stock returns occurred after $\mathrm{R} \& \mathrm{D}$ increase. Also, firms with $\mathrm{R} \& \mathrm{D}$ increase experience significantly positive abnormal long term operating performance compared to the firms without R\&D increase. Furthermore, Eberhart et al. (2004) insisted that the result didn't support the efficient market hypothesis (EMH) prediction. The market failed to reconcile with $\mathrm{R} \& \mathrm{D}$ expenditure as publicly available information. These controversial results of existing research indicate that there is a complex relation between the $R \& D$ expenditure and the financial market valuation. Oriani and Sobrero (2008) contributed to the understanding of the complex relation between the R\&D expenditure and the financial market valuation. They found that the market uncertainty and the technology uncertainty had moderating effects on the financial market valuation of the R\&D capital. So, they proved that the financial market evaluates the $R \& D$ capital in real option logic.

Then, how does the market react when the firm' $\mathrm{R} \& \mathrm{D}$ expenditure is unexpectedly increased? The unexpectedly increased R\&D expenditure suggests that the firm launches an untypical $R \& D$. In the beginning of the untypical $R \& D$, $R \& D$ leads to the increase of the firm's uncertainty. And the firm's uncertainty has various effects on the firm value. It raises firm's risk, and the discount rate of firm's future cash flow would be higher. Therefore, firm's NPV would decrease. However, the higher uncertainty induces the more return volatility. That indicates that the real option value of the $\mathrm{R} \& \mathrm{D}$ ascends. Therefore, the total effects of the unusual $\mathrm{R} \& \mathrm{D}$ are not clear.

\subsection{Valuation of R\&D in Real Option Logic}

The R\&D value in real option logic should consider both strategic value and the alternative value of not investing. Most of previous studies take into accounts only the net present value $(N P V)$ and growth option value. However, in this paper, we adopt valuation of R\&D expenditure which Oriani and Sobrero (2008) used. $\mathrm{R} \& \mathrm{D}$ value $(V(\mathrm{R} \& \mathrm{D}))$ is a function of $N P V$, growth option $(G)$, switch option $(S)$, and waiting option $(W)$. G is the growth opportunity when the demand in the market soars. Only the firms which come to have the technology from the R\&D activity can have growth opportunity. $S$ means benefit to develop following technology when the firms complete the R\&D. $W$ is benefit to prolong the investment of the R\&D.

\subsection{Industry Moderator}

There are moderators between $V(\mathrm{R} \& \mathrm{D})$ and $N P V, G, S$, and $W$. Growth oppor- 
tunity $(\delta)$ is an industry moderator. Folta and O'Brien (2004) studied that firms in fast expansion industries had more growth opportunity. Therefore, the more $G$ should be reflected in $V(\mathrm{R} \& \mathrm{D})$ in the industries with the higher growth rate. Green and Scotchmer (1995) consider technology cumulativeness $(\gamma)$, the degree to which future innovations build on previous ones. The higher $\gamma$ increases $S$ because it raises the possibility that the firm which has cumulated more technologies has the advantage of the switching option.

\subsection{Uncertainty Effects to $V(R \& D)$}

Uncertainties affect the $R \& D$ value in real option logic. The uncertainties are factors of volatility of the expected returns from R\&D investment. And the volatility is an important factor of an option value. Balachandra and Friar (1997) showed the R\&D success depends on more external factors than internal factors. And the technology and market influenced the success of R\&D. Therefore, market uncertainty $\left(U_{m}\right)$ and technological uncertainty $\left(U_{t}\right)$ have to be considered for the $R \& D$ valuation model. The market uncertainty is the degree to which the observed market demand diverges from the expected market demand. The technology uncertainty indicates the uncertainties that the dominant technology to drive the market is not clear.

Finally, the Equation (1) of the R\&D valuation model follows below:

$$
V(\mathrm{R} \& \mathrm{D})=N P V\left(U_{m}\right)+\delta \cdot G\left(U_{m}\right)+\gamma \cdot S\left(U_{T}\right)-W\left(U_{m}, U_{t}\right)
$$

\section{Hypotheses}

The change of the R\&D value is the determined by the change of the market uncertainty and technological uncertainty as time varies. The market uncertainty is, as we mentioned, the degree to which the observed market demand diverges from the expected market demand. The market uncertainty is related to $N P V, G$, and $W$. As the market uncertainty increases, $N P V$ decreases as a result of the higher risk adjusted rate. However, the declining rate of $N P V$ is reduced. Therefore, $N P V$ decreases slowly as market uncertainty rises. Also, $G$ and $W$ increase because the volatility of $G$ and $W$ rise following the market uncertainty increases. Nevertheless, $W$ has an upper limit of the option value. Trigeorgis (1996) stated that the ultimate benefit from $W$ was the additional R\&D expenditure when the investment progresses. However, $G$ doesn't have an upper boundary of its value. In conclusion, $N P V$ and $W$ affect the R\&D value more than $G$ when the market uncertainty is low. As the market uncertainty rises, the $\mathrm{R} \& \mathrm{D}$ value declines. However, $G$ dominates the $\mathrm{R} \& \mathrm{D}$ value as market uncertainty increases because the decreasing rate of $N P V$ descends and $W$ reach the upper boundary limit. This indicates that the $\mathrm{R} \& \mathrm{D}$ value increases as the market uncertainty grows.

As Oriani and Sobrero (2008) documented, there is a U-shaped relationship between the degree of the market uncertainty and the market valuation of R\&D. 
Furthermore, the change of the R\&D market value following unit change of the $\mathrm{R} \& \mathrm{D}$ varies with the market growth $(\delta)$. The financial market weighs more to firms' value in the higher growth industry. Therefore, in the low growth industry, the effect of $G$ doesn't dominate the value of R\&D. However, in the medium and high growth market, the $G$ affects firm value more than in the low growth market. The infection point of the market uncertainty at which the market value negatively associated with the market uncertainty turns to the positively associated market value with the market uncertainty is the lowest in the high growth market. Therefore, both the market growth and the infection point determine the positive or negative relation between the market uncertainty and the financial market value.

These paper focuses on the relation market value of the R\&D capital and the market uncertainty. To test this relation, the two way interaction of R\&D capital and the market uncertainty is important. Oriani and Sobrero (2008) found that the product of the R\&D capital and the market uncertainty was significantly associated with the market value of firms. Also, they concluded the moderating effects of the industry market growth by testing three way interaction of industry market growth, $R \& D$ capital and market uncertainty with the firm value. Therefore, we can assume that there exists the significant relation between the product of the R\&D capital and the market uncertainty and the financial market valuation of the firm. Also, the product of the R\&D capital, the market uncertainty, and the market growth would have significant relation, too. From this discussion, we have the following hypotheses, mainly depending on Oriani and Sobrero (2008)'s findings.

Hypothesis 1) In the short term, the financial market evaluates the unexpectedly increased $R \& D$ expenditure with the real option logic.

Hypothesis 1.1) The market value of the firms with the unexpectedly increased $R \& D$ expenditure is significantly associated with the product of the $R \& D$ capital and the market uncertainty.

Hypothesis 1.2) The market value of the firms with the unexpectedly increased $R \& D$ expenditure is significantly associated with the product of the $R \& D$ capital, the market uncertainty, and the market growth.

Technological uncertainty is generated when it is not clear which technology will dominate in an industry. This technological uncertainty increases both $S$ and $W$ through volatility. However, the R\&D value doesn't vary linearly. $S$ increases the R\&D value, but $W$ is subtracted. As we mentioned above, $W$ has an upper bound. $S$ has an also upper bound. $S$ is an option on the difference between the values of the new technology and the established one. When the previous technology is perfectly substituted by the new technology, $S$ has maximum value, because the value of previous technology is zero. On the other hand, $W$ is minimum because the technology uncertainty doesn't exist. Therefore, when the technology uncertainty is low, the $S$ value affects the R\&D value more than the $W$. However, as the technology uncertainty increases, the $\mathrm{W}$ value grows. Mar- 
ket weighs R\&D value through the technology cumulativeness, $\gamma$. The $S$ is more valuable when the industry technology cumulativeness, $\gamma$, is higher.

Oriani and Sobrero (2008) argued that there is an inverse U-shaped relationship between the degree of the technological uncertainty and the market valuation of the $R \& D$ capital. Also, the slope of the $R \& D$ market value is a convex function of the technological uncertainty and varies by the technology cumulativeness $(\gamma)$.

Therefore, both the technology cumulativeness and the infection point determine either positive or negative relation between the technology uncertainty and the financial market value. Their paper tests on the relation market value of the $\mathrm{R} \& \mathrm{D}$ capital and the technology uncertainty. We have to examine whether the two way interaction of R\&D capital and the technology uncertainty has significant relation with the firm value. Oriani and Sobrero (2008) found that the product of the R\&D capital and the technology uncertainty was significantly associated with the market value of firms. Also, they concluded the moderate effects of the industry technology cumulativeness by testing three way interaction of industry technology cumulativeness, R\&D capital and technology uncertainty with the firm value. Therefore, we can assume that there exists the significant relation between the product of the R\&D capital and the technology uncertainty, and the financial market valuation of the firm. Also, the product of the R\&D capital, the technology uncertainty, and technology cumulativeness would have significant relation, too. From this discussion, the following hypotheses are set up, also mainly resting on Oriani and Sobrero (2008)'s arguments.

Hypothesis 1.3) The market value of the firms with the unexpectedly increased $R \& D$ expenditure is significantly associated with the product of the $R \& D$ capital and the technology uncertainty.

Hypothesis 1.4) The market value of the firms with the unexpectedly increased $R \& D$ expenditure is significantly associated with the product of the $R \& D$ capital, the technology uncertainty, and technology cumulativeness.

Sougiannis (1994) stated that investors placed a high value on R\&D investments. On average, a one-dollar increase in $\mathrm{R} \& \mathrm{D}$ expenditure produces a five dollar increase in the market value. Also, a one-dollar increase in R\&D expenditures leads to a two dollar increase in profit over 7 years. From this, we have,

Hypothesis 2) In the long term, the market value of the firms with the unexpectedly increased $R \& D$ expenditure is significantly associated with the product of the $R \& D$ capital and the operational performance.

\section{Method}

\subsection{The Hedonic Model}

As many previous studies suggest, we use hedonic model [as shown in Equation (2)] in order to estimate firm value in terms of the assets. Hall (2000) suggested to include both the tangible assets and intangible assets for the asset valuation. However, in this paper, we consider only R\&D capital among the intangible as- 
sets because there isn't enough evidence of association between other intangible assets and the market value of the firm. An Equation (2) expresses the firm market value as a function of tangible asset $(A), \mathrm{R} \& \mathrm{D}$ capital $(K)$.

$$
V=b(A+\chi K)
$$

where $b$ is the market valuation coefficient of the firm value. $\chi$ is the market valuation coefficient of a firm's R\&D capital.

So, if we divide the Equation (2) by $A$ and take the natural logs, the Equation (3) is following:

$$
\log (V / A)=\log b+\log (1+\chi K / A)
$$

To verify the hypothesis 1.1 and hypothesis 1.3 , the market uncertainty $\left(U_{m}\right)$ and the technology uncertainty $\left(U_{t}\right)$ as moderators in valuing firms' R\&D capital $(K)$ have to be added to the Equation (3). Also, the impact of the market uncertainty $\left(U_{m}\right)$ and the technology uncertainty $\left(U_{t}\right)$ to firms' $\mathrm{R} \& \mathrm{D}$ value varies by the industry moderators, the industry market growth $(\delta)$ and the industry technology cumulativeness $(\gamma)$ as we assumed hypothesis 1.2 and 1.4. Finally, to examine the hypothesis 2 , the operational performance $(P)$ is added as a moderator of $\mathrm{R} \& \mathrm{D}$ capital $(K)$ to Equation (3). $C$ is the control variable including sales to handle size effect.

$$
\begin{aligned}
\log (V / A)= & \log b+\log \left(1+\chi K / A+\omega_{m} U_{m}+\omega_{t} U_{t}+\pi_{\delta} \delta+\pi_{\gamma} \gamma\right. \\
& +\theta_{m} K / A \cdot U_{m}+\varepsilon_{m} K / A \cdot U_{m} \cdot \delta+\theta_{t} K / A \cdot U_{t} \\
& \left.+\varepsilon_{t} K / A \cdot U_{t} \cdot \gamma+\alpha \cdot P+\beta \cdot K / A \cdot P+\rho \cdot C\right)
\end{aligned}
$$

where $\omega_{m}$ is the market valuation coefficient of the market uncertainty, $\omega_{t}$ is the market valuation coefficient of the technology uncertainty, $\pi_{\delta}$ is the market valuation coefficient of the industry market growth, $\pi_{\gamma}$ is the market valuation coefficient of the industry technology cumulativeness, $\theta_{m}$ is the market valuation coefficient of the product of the normalized $\mathrm{R} \& \mathrm{D}$ capital $(K / A)$ and the market uncertainty, $\varepsilon_{m}$ is the market valuation coefficient of the product of the normalized $\mathrm{R} \& \mathrm{D}$ capital, the market uncertainty and the industry market growth, $\theta_{t}$ is the market valuation coefficient of the product of the normalized $\mathrm{R} \& \mathrm{D}$ capital and the technology uncertainty, $\varepsilon_{t}$ is the market valuation coefficient of the product of the normalized $\mathrm{R} \& \mathrm{D}$ capital, the technology uncertainty and the industry technology cumulativeness, $\alpha$ is the market valuation coefficient of the operational performance, $\beta$ is the market valuation coefficient of the product of the normalized $\mathrm{R} \& \mathrm{D}$ capital and the operational performance, and $\rho$ is the market valuation coefficient of the control variable $(C)$.

Formula (4) shows how the financial value of the firms is affected by independent variables at time $t$. To examine hypotheses, we need to observe the coefficients of Equation (4) from the beginning year (year 0) when the R\&D expenditure is unexpectedly increased up to the 4th year. Cho and Chung (2001) adopt Lev and Sougiannis (1996)'s research method to Korean data. They found that 1 won of (Korean currency) of R\&D expenditures generates 1.25 won of earnings, 
on average, over the following 2 - 4 years, including the year of expenditures.

We regresses the market value of the firm at year 0 on the independent variables of Equation (4) from the year 0 to the year 4, because the financial market values the $R \& D$ capital in terms of the market and technology uncertainties, the industry growth, and the technology cumulativeness that are generated not only at present but also in the future with real option logic. And then, the same regression adapts to the market value of the firm from the year 1 to the year 4 . For example, the market value of the firm at year 1 is regressed with the independent variables of Equation (4) from the year 1 to the year 4 .

\subsection{Firms}

In this paper, we examine the data of firms in operation from 1999 to 2008 which are listed in both Korea Composite Stock Price Index (KOSPI) and Korea Securities Dealers Automated Quotation (KOSDAQ).

\subsection{R\&D Capitalization}

We consider the firms' R\&D expenditure as an intangible asset. Many researchers concluded that the $\mathrm{R} \& \mathrm{D}$ expenditure has an asset characteristic rather than an expense. The methods to capitalize the $\mathrm{R} \& \mathrm{D}$ expenditure are various. According to Korean accounting standards, there are three categories for the R\&D expenditure. The $\mathrm{R} \& \mathrm{D}$ expenditure in the research stage is expensed immediately as the research expenses in the income statement. The R\&D expenditure in the development stage is divided into intangible capital and expense. This R\&D expenditure is capitalized as improvements cost when the technologies are feasible and the future economic profit is probable. The depreciation of the $\mathrm{R} \& \mathrm{D}$ capital is various by companies. The other $\mathrm{R} \& \mathrm{D}$ expenditure in the development stage is expensed as the ordinary development expense in the income statement. Which category a firm adopts to deal with each $R \& D$ expenditure totally depends on the firm's judgment. And in this paper, we include the total of R\&D expenditures, whether it is at the research stage or at the development stage and whether it is capitalized or expensed. So, the firms' $\mathrm{R} \& \mathrm{D}$ expenditure $(R)$ in a $t$ year is

$$
\begin{aligned}
R_{t}= & \text { research expense }_{t}+\text { ordinary development expense }_{t} \\
& + \text { capiatalized improvement cost }_{t}
\end{aligned}
$$

The R\&D expenditures are capitalized in the form of the R\&D capital method suggested by Grilches and Mairesse (1984) and Hall (1996). Generally, a constant annual 15 percent depreciation rate of past R\&D expenditures is accepted.

$$
K_{t}=(1-0.15) K_{t-1}+R_{t}
$$

\subsection{Unexpectedly Increased R\&D Expenditure}

Unexpectedly increased R\&D expenditure must satisfy four conditions. First, the ratio of industry R\&D expenditure to sales in 2007 and 2008 must be higher than $0.5 \%$. The industries whose $\mathrm{R} \& \mathrm{D}$ activity is not important for firm operation are 
not included in this paper. Second, the firms with higher ratio of R\&D expenditure to sales (higher than 3\%) from 1999 to 2003 are considered. Third, the absolute $R \& D$ expenditure must increase $5 \%$ or higher compared to the last year. Fourth, the ratio of $\mathrm{R} \& \mathrm{D}$ expenditure to asset or the ratio of $\mathrm{R} \& \mathrm{D}$ expenditure to sales must go up $5 \%$ or higher than the previous year.

After the first condition is applied, only several industries are left, as we can from Table 1. In this paper, the 9th KOREA standard industry classification code with level 2 (revised in 2007) is used.

\subsection{Market Uncertainty}

Market uncertainty $U_{m, i, t}$ is defined as the unexpected demand in the market. Therefore, the market uncertainty can be derived from the difference between the real industry output $I_{i, t}$ and the forecasted industry output $\bar{I}_{i, t}$. And the difference should be divided by the real industry output to eliminate the industrial size effect as of Equation (7).

$$
U_{m, i, t}=\frac{I_{i, t}-\bar{I}_{i, t}}{I_{i, t}}
$$

where $i$ means industry and $t$ means time.

The Korean real industry output is available from the Structural Analysis database (STAN) from the Organization for Economic Co-operation and Development (OECD) during the period of 1981-2007. The Korean forecasted industry output is simulated based on the real industry output above with the first order Autoregressive model, AR(1). The annual industry output is a function of the first-order lag of the industry output.

Table 1. Industry list with the R\&D intensity in 2007 and $2008^{1,2}$.

\begin{tabular}{lcc}
\hline \multicolumn{1}{c}{ Industry } & 2007 & 2008 \\
\hline C21 Pharmaceuticals, medicinal chemicals and botanical products & 3.44 & 4.45 \\
C26 Electronic components, computer, radio, television and & 5.29 & 4.94 \\
communication equipment and apparatuses & 1.55 \\
C28 Electrical equipment & 1.45 & 1.76 \\
C29 Other machinery and equipment & 1.52 & 1.96 \\
C30 Motor vehicles, trailers and semitrailers & 1.94 & 2.72 \\
J Information and communications & 1.94 & \\
\hline
\end{tabular}

${ }^{1}$ It is known that R\&D activities improve the innovative and product development capabilities of manufacturing. Manufacturing-related R\&D fosters new product and process development by companies to utilize "computer-aided and expert systems for design, process and materials selection, life-cycle cost estimation, rapid prototyping, and tooling” (NIST, 2019). R\&D efforts in manufacturing bring improvements in existing methods or processes and also create new manufacturing processes along with new product developments. R\&D activities are more prominent in manufacturing industries in comparison to other industries. However, the increased $R \& D$ expenditures in the manufacturing may incur short-term uncertainties on the firm value, due to the undetermined future of commercialization and market demand on the new products from $R \& D$ and innovation. ${ }^{2} R \& D$ intensity is defined as " $R \& D$ expenditure to sales". 


$$
\bar{I}_{i, t}=\beta \bar{I}_{i, t-1}+\varepsilon_{i, t}
$$

where $\beta$ is the coefficient of the forecasted industry output and $\varepsilon_{i, t}$ is an error term.

The financial time series usually shows volatility clustering. Folta and O'Brien (2004) mentioned that the Generalized Autoregressive Conditional Heteroskedastcity (GARCH) model improves goodness of fit in the case above. $\sigma_{i, t}$ is defined as a time-dependent standard deviation of the error term, $\tau_{i, t}$ is defined as a stochastic piece of the variance of the error term.

$$
\varepsilon_{i, t}=\sigma_{i, t} \tau_{i, t}
$$

In $\operatorname{GARCH}(1,1)$ model, the variance of the error term is affected by the first-order lag of the variance itself and the squared error term.

$$
\sigma_{i, t}^{2}=\theta_{0}+\theta_{1} \varepsilon_{i, t-1}^{2}+\phi_{1} \sigma_{i, t-1}^{2}
$$

where $\theta_{0}$ is a constant, $\theta_{1}$ is a coefficient of the squared error term and $\phi_{1}$ is a coefficient of the variance of the error term.

\subsection{Technology Uncertainty}

The technology uncertainty indicates that the several technologies compete to commercialize and the dominate technology is not clear. In this paper, the inverse of Technology Cycle Time (TCT) represents technology uncertainty. TCT is the period that the new technology gets developed based on the previous technology. Oriani and Sobrero (2008) use the citation lag of the patents data to estimate TCT because the patent citation lag means the time that the technology of the referencing patent improves the technology of the referenced patent. The short TCT indicates that the main technology of industry changes fast. Therefore, the industry with the shorter TCT has more technology uncertainty compared to the industry with the longer TCT. And the inverse of TCT represents the technology uncertainty. In this paper, the citation lag is defined the average mean period from the grant year of the referenced patent to the grant year of the referencing patent. The backward citation lag is used to measure TCT.

To measure the TCT, we use the U.S. patent data from NBER. However, there are two problems to extract the TCT from 1999 to 2008 of industries. One is that the patent data is available only from 1964 to 1999 . Therefore, the TCT from 1999 to 2008 of industries is statistically predicted by AR(1) and GARCH(1). Second problem is that the classification of patents doesn't match the industry classification. The classification of patents is function oriented. The concordance table between the U.S. Patent Classification System (USPCS) (as of December 31, 2005) and 41 unique product fields based on the 1972 Standard Industrial Classification System (SIC) is used to transform the patent classification to industry classification.

\subsection{Operational Performance}

As with many similar researches (Grant, 1984), corporate performance is meas- 
ured by sales growth. The advantage of sales growth as an indicator of a firm's external growth is that it is linked with the firm's market share. Since corporate performance by investments in R\&D tends to produce results after 2 or 4 years (Jo \& Jung, 2001), we calculated the annual sales growth from the year when the $\mathrm{R} \& \mathrm{D}$ expenditure is unexpectedly increased up to the 4 th year

\subsection{Market Growth}

Market growth is the industry growth of the market in Korea. The OECD STAN database provides the Korean industry output from 1981 to 2007. The market growth is the industry output growth rate compared to the previous year.

\subsection{Technology Cumulativeness}

Technology cumulativeness is the degree of the patent self-citations by the interpretation of Lanjouw and Shankerman (2001). The patent self-citation is that the patentee cites the patent of the same patentee. When the patentee cites own patent, it means that the technology of the previous patent is used to develop further technology. Therefore, the technology cumulativeness is defined as the patent backward self-citation divided by the patent total backward citations calculated at the industry level. The U.S. patent citation data of NBER from 1964 to 1999 is used. As it is mentioned in the technology uncertainty section, there are two problems, the time and industry classification mismatch of data. It will be solved at the same way.

\subsection{Other Variables}

Market value of the firm $(V)$ is the firm value evaluated by financial market. It is defined as the sum of the market capitalization at 12/31, loan capital, and short-term borrowing. Book value of tangible assets $(A)$ is the total assets minus the current liabilities without short term borrowing and less intangible assets.

$$
A=\text { total asset - (current lialities - short term borrowing) - intangible asset }
$$

The control variable $(C)$ is the sales which are taken by $\log 10$. It needs to control the size effects.

\subsection{Descriptive Statistics and Correlations}

In Table 2, descriptive statistics and correlations for the ratio $V / A, K / A$, and the total sales of the firm are presented. Also, the market and technology uncertainty, the market growth, and the technology cumulativeness are included. The number of sample firms is 37 and it is relatively small. This is because we applied strict conditions of the unexpectedly increased R\&D expenditures. The mean and the standard deviation of 7 variables from year 0 to the year 4 are found in Table 2. In year 0 , the mean of $V / A$ is 1.32 . Also, the mean of $V / A$ is 1.27 in year 1. From the year 2 to the year 4 , the mean of $V / A$ increases from 1.58 to 1.66 . In year 0 , the mean of $K / A$ is 0.13 . Also, the mean of $K / A$ is 0.26 in year 1 . On the 
Table 2. Descriptive statistics and correlations.

\begin{tabular}{|c|c|c|c|c|c|c|c|c|c|}
\hline & Mean & $\begin{array}{l}\text { Standard } \\
\text { deviation }\end{array}$ & $\begin{array}{l}\text { Firm value/ } \\
\text { Tangible asset }\end{array}$ & $\begin{array}{l}\text { R\&D capital/ } \\
\text { Tangible asset }\end{array}$ & $\begin{array}{l}\text { Log } \\
\text { (Sales) }\end{array}$ & $\begin{array}{c}\text { Market } \\
\text { uncertainty }\end{array}$ & $\begin{array}{l}\text { Technology } \\
\text { uncertainty }\end{array}$ & $\begin{array}{l}\text { Market } \\
\text { growth }\end{array}$ & $\begin{array}{c}\text { Technology } \\
\text { cumulativeness }\end{array}$ \\
\hline \multicolumn{10}{|l|}{ Year 0} \\
\hline Firm value/Tangible asset & 1.32 & 1.32 & 1.00 & & & & & & \\
\hline $\mathrm{R} \& \mathrm{D}$ capital/Tangible asset & 0.13 & 0.28 & -0.19 & 1.00 & & & & & \\
\hline Log (Sales) & 10.89 & 1.12 & $-0.35^{\star *}$ & -0.18 & 1.00 & & & & \\
\hline Market uncertainty & 1.36 & 0.20 & -0.41 & 0.12 & $0.32^{*}$ & 1.00 & & & \\
\hline Technology uncertainty & 0.10 & 0.02 & $0.44^{\star *}$ & $-0.36^{\star \star}$ & -0.20 & $-0.86^{\star \star \star}$ & 1.00 & & \\
\hline Market growth & 0.09 & 0.19 & -0.19 & $1.00^{* * *}$ & $-0.17^{\star}$ & 0.13 & $-0.37^{\star \star}$ & 1.00 & \\
\hline Technology cumulativeness & 0.11 & 0.02 & -0.12 & -0.08 & 0.14 & -0.05 & -0.08 & -0.08 & 1.00 \\
\hline \multicolumn{10}{|l|}{ Year 1} \\
\hline Firm value/Tangible asset & 1.27 & 0.76 & 1.00 & & & & & & \\
\hline $\mathrm{R} \& \mathrm{D}$ capital/Tangible asset & 0.26 & 0.49 & 0.02 & 1.00 & & & & & \\
\hline Log (Sales) & 10.79 & 1.08 & $-0.35^{\star *}$ & -0.03 & 1.00 & & & & \\
\hline Market uncertainty & 1.31 & 0.23 & -0.22 & 0.05 & 0.17 & 1.00 & & & \\
\hline Technology uncertainty & 0.10 & 0.02 & $0.29^{*}$ & 0.05 & -0.18 & $-0.86^{\star * *}$ & 1.00 & & \\
\hline Market growth & 0.07 & 0.10 & -0.08 & -0.10 & 0.25 & $-0.51^{\star * *}$ & 0.24 & 1.00 & \\
\hline Technology cumulativeness & 0.11 & 0.02 & -0.12 & -0.12 & 0.19 & -0.10 & -0.07 & 0.05 & 1.00 \\
\hline \multicolumn{10}{|l|}{ Year 2} \\
\hline Firm value/Tangible asset & 1.58 & 1.60 & 1.00 & & & & & & \\
\hline $\mathrm{R} \& \mathrm{D}$ capital/Tangible asset & 0.28 & 0.49 & $0.36^{\star *}$ & 1.00 & & & & & \\
\hline Log (Sales) & 10.88 & 1.10 & -0.20 & 0.23 & 1.00 & & & & \\
\hline Market uncertainty & 1.24 & 0.21 & -0.13 & 0.24 & 0.11 & 1.00 & & & \\
\hline Technology uncertainty & 0.10 & 0.02 & 0.19 & -0.10 & -0.19 & $-0.84^{\star * *}$ & 1.00 & & \\
\hline Market growth & 0.08 & 0.07 & -0.12 & 0.06 & $0.39^{* *}$ & 0.10 & $-0.29^{*}$ & 1.00 & \\
\hline Technology cumulativeness & 0.11 & 0.02 & -0.01 & -0.13 & 0.18 & -0.22 & -0.07 & $0.29^{*}$ & 1.00 \\
\hline \multicolumn{10}{|l|}{ Year 3} \\
\hline Firm value/Tangible asset & 1.63 & 1.00 & 1.00 & & & & & & \\
\hline $\mathrm{R} \& \mathrm{D}$ capital/Tangible asset & 0.20 & 0.24 & 0.01 & 1.00 & & & & & \\
\hline Log (Sales) & 10.96 & 1.14 & $-0.34^{\star \star}$ & $0.34^{* *}$ & 1.00 & & & & \\
\hline Market uncertainty & 1.17 & 0.18 & $-0.38^{* *}$ & 0.13 & 0.01 & 1.00 & & & \\
\hline Technology uncertainty & 0.10 & 0.02 & $0.37^{\star *}$ & -0.04 & -0.21 & $-0.79^{* * *}$ & 1.00 & & \\
\hline Market growth & 0.09 & 0.09 & -0.05 & 0.18 & $0.33^{* *}$ & 0.11 & $-0.39^{* *}$ & 1.00 & \\
\hline Technology cumulativeness & 0.11 & 0.02 & 0.03 & -0.16 & 0.16 & -0.19 & -0.08 & -0.12 & 1.00 \\
\hline \multicolumn{10}{|l|}{ Year 4} \\
\hline Firm value/Tangible asset & 1.66 & 1.33 & 1.00 & & & & & & \\
\hline $\mathrm{R} \& \mathrm{D}$ capital/Tangible asset & 0.15 & 0.11 & -0.09 & 1.00 & & & & & \\
\hline Log (Sales) & 11.02 & 1.09 & $-0.32^{*}$ & 0.08 & 1.00 & & & & \\
\hline Market uncertainty & 1.12 & 0.14 & $-0.35^{\star *}$ & $0.34^{* *}$ & 0.20 & 1.00 & & & \\
\hline Technology uncertainty & 0.10 & 0.02 & $0.34^{* *}$ & -0.22 & -0.24 & $-0.83^{* * *}$ & 1.00 & & \\
\hline Market growth & 0.07 & 0.09 & -0.12 & -0.02 & -0.20 & 0.08 & -0.23 & 1.00 & \\
\hline Technology cumulativeness & 0.11 & 0.02 & 0.04 & -0.13 & 0.17 & -0.25 & -0.09 & 0.02 & 1.00 \\
\hline
\end{tabular}

${ }^{\star} p<0.10 ;{ }^{* *} p<0.05 ;{ }^{* * *} p<0.01$. The number of sample firms is 37. 
other hand, from the year 2 to the year 4 , the mean of $K / A$ decreases from 0.28 to 0.15 . In Table 2, the coefficient of correlation of 7 variables is shown. The market uncertainty and the technology uncertainty are strongly correlated from the year 0 to the year 4 . Therefore, the variance inflation factor (VIF) test of 7 variables was conducted. For all models, the VIF was below the critical value of 10. Therefore, there is no problem for the regression.

\section{Results (Table 3)}

First, the regression between $\log (V / A)$ in year 0 and the independent variables from the year 0 to the year 4 show many significant relationships. The regression

Table 3. Results of regression.

\begin{tabular}{|c|c|c|c|c|c|c|c|c|c|c|c|c|c|c|c|}
\hline & Year 0 & Year 1 & Year 2 & Year 3 & Year 4 & Year 1 & Year 2 & Year 3 & Year 4 & Year 2 & Year 3 & Year 4 & Year 3 & Year 4 & Year 4 \\
\hline & Year 0 & & & & & Year 1 & & & & Year 2 & & & Year 3 & & Year 4 \\
\hline \multirow{2}{*}{$\mathrm{K} / \mathrm{A}$} & 1.61 & $-0.55^{\star * *}$ & $-0.55^{\star * *}$ & $-1.08^{* * *}$ & $-1.23^{* *}$ & -0.01 & 0.01 & -0.03 & -0.05 & 0.11 & -0.03 & -0.09 & -0.08 & 0.30 & 0.07 \\
\hline & 1.29 & 0.11 & 0.11 & 0.23 & 0.61 & 0.10 & 0.10 & 0.21 & 0.45 & 0.11 & 0.22 & 0.48 & 0.21 & 0.45 & 0.46 \\
\hline \multirow{2}{*}{$K / A^{*} U_{m}$} & 0.58 & $-0.43^{\star * *}$ & $-0.40^{* * *}$ & $-0.87^{\star * *}$ & $-0.98^{\star * *}$ & -0.02 & 0.00 & -0.04 & -0.10 & 0.07 & -0.07 & -0.17 & -0.11 & 0.19 & 0.03 \\
\hline & 0.93 & 0.07 & 0.08 & 0.18 & 0.47 & 0.07 & 0.07 & 0.16 & 0.35 & 0.07 & 0.17 & 0.37 & 0.16 & 0.35 & 0.35 \\
\hline \multirow{2}{*}{$K / A^{\star} U_{t}$} & $21.59^{* *}$ & $-4.09^{* * *}$ & $-5.52^{\star * *}$ & $-9.13^{* * *}$ & -10.44 & 0.29 & 0.34 & 0.40 & 1.60 & 1.49 & 0.76 & 2.81 & 0.25 & 5.39 & 1.94 \\
\hline & 10.39 & 1.22 & 1.25 & 2.61 & 7.07 & 0.98 & 1.09 & 2.12 & 5.09 & 1.12 & 2.23 & 5.34 & 2.13 & 5.03 & 5.15 \\
\hline \multirow{2}{*}{$K / A^{*} p$} & -2.25 & $0.67^{* * *}$ & $0.00^{* *}$ & $-0.04^{* *}$ & -0.06 & 0.04 & 0.00 & 0.00 & 0.07 & 0.00 & 0.00 & -0.02 & -0.02 & 0.20 & 0.22 \\
\hline & 1.81 & 0.17 & 0.00 & 0.02 & 0.25 & 0.14 & 0.00 & 0.01 & 0.18 & 0.00 & 0.01 & 0.19 & 0.01 & 0.18 & 0.18 \\
\hline \multirow{2}{*}{$K / A^{*} U_{m}{ }^{*} \delta$} & -1.83 & -0.50 & $-4.44^{* * *}$ & $-5.44^{* * *}$ & -2.24 & -0.15 & -0.11 & -0.58 & 0.57 & 0.40 & -0.19 & -4.69 & -0.56 & -2.10 & -1.53 \\
\hline & 1.90 & 0.89 & 0.83 & 0.88 & 3.94 & 0.62 & 0.79 & 0.89 & 2.76 & 0.83 & 0.94 & 2.79 & 0.89 & 2.75 & 2.78 \\
\hline \multirow{2}{*}{$K / A^{*} U_{t}^{*} \gamma$} & $205.70^{*}$ & $-39.64^{* * *}$ & $-53.30^{* * *}$ & $-89.09^{* * *}$ & -104.13 & 2.67 & 3.17 & 3.40 & 11.19 & 14.42 & 7.76 & 29.92 & 3.01 & 55.44 & 25.07 \\
\hline & 101.51 & 11.67 & 11.92 & 25.01 & 67.35 & 9.42 & 10.47 & 20.45 & 48.60 & 10.76 & 21.51 & 50.96 & 20.54 & 47.91 & 49.07 \\
\hline \multirow{2}{*}{$U_{m}$} & $-0.67^{* *}$ & $-0.64^{\star *}$ & $-0.62^{*}$ & $-0.69^{*}$ & $-0.91^{*}$ & -0.19 & -0.15 & -0.27 & -0.51 & -0.29 & $-0.65^{\star *}$ & -0.58 & -0.48 & -0.43 & -0.52 \\
\hline & 0.33 & 0.29 & 0.33 & 0.40 & 0.49 & 0.22 & 0.24 & 0.29 & 0.35 & 0.25 & 0.29 & 0.36 & 0.28 & 0.35 & 0.35 \\
\hline \multirow{2}{*}{$U_{t}$} & $5.84^{* *}$ & $5.88^{* *}$ & $5.91^{* *}$ & $5.93^{* *}$ & $5.96^{* *}$ & 2.63 & 2.64 & 2.66 & 2.68 & 3.48 & 3.50 & 3.53 & 3.03 & 3.03 & 2.98 \\
\hline & 2.80 & 2.82 & 2.85 & 2.87 & 2.90 & 2.04 & 2.06 & 2.08 & 2.10 & 2.14 & 2.16 & 2.18 & 2.07 & 2.09 & 2.11 \\
\hline \multirow{2}{*}{$\delta$} & -0.26 & 0.58 & -1.47 & -0.75 & -0.43 & -0.60 & -0.75 & 0.08 & 0.27 & -1.25 & 0.69 & -1.07 & 0.07 & -0.86 & -0.45 \\
\hline & 0.38 & 0.77 & 1.03 & 0.74 & 0.90 & 0.53 & 0.73 & 0.53 & 0.63 & 0.75 & 0.54 & 0.64 & 0.53 & 0.61 & 0.63 \\
\hline \multirow{2}{*}{$\gamma$} & -1.18 & -1.06 & -1.00 & -0.99 & -0.98 & -0.94 & -0.88 & -0.85 & -0.84 & 1.52 & 1.51 & 1.49 & 1.85 & 1.84 & 2.24 \\
\hline & 4.22 & 4.13 & 4.09 & 4.07 & 4.05 & 2.88 & 2.85 & 2.84 & 2.83 & 3.00 & 2.98 & 2.97 & 2.84 & 2.83 & 2.84 \\
\hline \multirow{2}{*}{$P$} & -0.25 & 0.18 & $0.00^{* *}$ & $-0.04^{* *}$ & 0.01 & -0.05 & 0.00 & 0.00 & 0.04 & 0.00 & 0.00 & 0.02 & -0.02 & 0.08 & 0.08 \\
\hline & 0.18 & 0.14 & 0.00 & 0.02 & 0.08 & 0.10 & 0.00 & 0.01 & 0.05 & 0.00 & 0.02 & 0.06 & 0.01 & 0.05 & 0.05 \\
\hline \multirow{2}{*}{$\log (S)$} & $-0.21^{* * *}$ & $-0.13^{*}$ & $-0.19^{* * *}$ & $-0.19^{* * *}$ & $-0.20^{* * *}$ & $-0.14^{*}$ & $-0.14^{* * *}$ & $-0.13^{* * *}$ & $-0.14^{* * *}$ & -0.08 & -0.07 & -0.07 & $-0.11^{* *}$ & -0.11 & $-0.12^{* * *}$ \\
\hline & 0.05 & 0.06 & 0.06 & 0.05 & 0.06 & 0.04 & 0.04 & 0.04 & 0.04 & $0.05^{*}$ & 0.04 & 0.05 & 0.04 & 0.04 & 0.04 \\
\hline
\end{tabular}

${ }^{\star} p<0.10 ;{ }^{* *} p<0.05 ;{ }^{* * *} p<0.01$. Dependent variable is $\log 10(V / A)$. 
results of firm value in year 0 and the independent variables in year 0 support that hypothesis 1.1 and hypothesis 1.2 are rejected. It fails to find the significant relation between the market value of the firm and the product of the R\&D capital and the market uncertainty. Also, it fails to show the evidence of the significant relation between the market value of the firm and the product of the R\&D capital, the market uncertainty, and the market growth. However, the hypothesis 1.3 and hypothesis 1.4 are supported. The coefficient of the regression between the market value of the firm in year 0 and the product of the R\&D capital and the technology uncertainty is 21.59 . This shows that the technology uncertainty has a strong moderator role between the market value of the firm and the R\&D capital. The coefficient of the regression between the market value of the firm in year 0 and the product of the R\&D capital, the technology uncertainty and the technology cumulativeness is 205.70 .

The regression results of firm value in year 0 and the independent variables from the year 1 to the year 4 support hypothesis 1.1. The product of the market uncertainty and the R\&D capital has a significantly negative relationship with the financial market value of the firm. The firms' market uncertainty from the year 1 to the year 4 is lower than the infection point at which the market value negatively associated with the market uncertainty turns to the positively associated market value with the market uncertainty because the relation between the market uncertainty and the market value of the firm has $U$ shape and the product of the market uncertainty and the R\&D capital negatively associate with the firm value. From the year 2 to the year 3, the hypothesis 1.2 is supported. The product of the market uncertainty, the R\&D capital, and the market growth has a significant negative relationship with the financial market value of the firm. By the regression results of firm value in year 0 and the independent variables from the year 1 to the year 4 , the hypothesis 1.3 is supported. The product of the technology uncertainty and the R\&D capital has a significantly negative relationship with the financial market value of the firm. The technology uncertainty from the year 1 to the year 4 is above the infection point at which the market value positively associated with the technology uncertainty turns to the negatively associated market value with the technology uncertainty because the relation between the technology uncertainty and the market value of the firm has inverse $U$ shape and the product of the technology uncertainty and the R\&D capital negatively associates with the firm value. From the year 2 to the year 4 , the hypothesis 1.4 is supported. The product of the technology uncertainty, the R\&D capital, and the technology cumulativeness has significantly negative relationship with the financial market value of the firm.

An interesting point is that the market uncertainty and the technology uncertainty from year 0 to the year 4 are significantly associated with the market value of the firm in year 0 . This implies that the market uncertainty and the technology uncertainty respectively affected the market valuation without the moderator role of the R\&D capital. The market uncertainty is negatively associated with the 
market value of the firm. This indicates that the growth option value is lower than the waiting option value.

Therefore, when we take only growth option into account, the market valuation of the R\&D capital can be misunderstood. The technology uncertainty is positively associated with the market value of the firm. The switching option is more valuable than the waiting option.

From these results, we can say that the financial market evaluates the firms' $R \& D$ capital with the real option logic. Firm value of the year 0 is significantly associated with the market uncertainty and the technology uncertainty.

However, the firm value from the year 1 to the year 4 rejects the hypothesis 1.1 , hypothesis 1.2 , hypothesis 1.3 , hypothesis 1.4 and hypothesis 2 . No coefficients have significant $p$-value except for the sales in log scale and the firm value.

Our result also shows that the period during which the uncertainty affects the firm value is less than a year. Cho and Jung (2001) reported that it took 2 or 4 year to improve the operational performance by R\&D. So this period seems to be much shorter than usual expectation suggests.

\section{Conclusion}

The financial market seems to evaluate the unexpectedly increased R\&D capital with real option logic. Our result is in line with the previous research (for example, Eberhart et al., 2004). When a firm raises the R\&D capital unexpectedly, this provides a signal to the financial market that the uncertainty around firm goes up. Nonetheless, the market reflects the uncertainty change into its market value of the firm. The uncertainty of market and technology changes, which leads to the fluctuation of the value of $R \& D$ capital. Therefore, abnormal return of the $R \& D$ capital unexpectedly increased.

The market valuation considers not only the market uncertainty and the technology uncertainty at the time that the R\&D expenditure unexpectedly increased but also takes into account the market uncertainty and the technology uncertainty of the future. That shows that the market value of the firm has a significant relationship with the market uncertainty and the technology uncertainty, respectively, and the product of the R\&D capital and either the market uncertainty or the technology uncertainty. However, the uncertainty effects don't last over time. These effects are only significant right after the R\&D capital unexpectedly increased. And the period is shorter than 1 year. This is because the decreasing rate of option value is varying over time. Usually, the declining rate is small when the option expiration date is far from now. However, as the option expiration date approaches, the option value is exponentially decreasing. The result shows that the operational performance doesn't have any relationship with the firm value. This result doesn't fit into the previous research.

In our research, the mismatch of the firm data and the patent data was solved by statistical prediction. However, NBER is expected to post new latest patent data in 2010. Therefore, we are planning to examine a new analysis using these 
new patent data in next version of this research paper.

In this research, we assume that unexpected $R \& D$ expenditures generate market and technology uncertainties and are reflected in the valuation of the firm with the real option logic when they are evaluated in financial markets. We find empirical evidence that the financial market takes account of these uncertainties of $R \& D$, using Korean market and firm data. The variables we used to test our hypotheses can be defined in a similar way for the valuation of the firms in other financial markets and the public data on the variable are accessible in those markets, too. A body of research states that $\mathrm{R} \& \mathrm{D}$ expenditures increase uncertainties for the valuation of the firms; this paper is one of the research that examines the relationship between R\&D capital and firm value. Theoretical logic and empirical evidence from this paper can be generalizable to other financial markets, too.

\section{Conflicts of Interest}

The authors declare no conflicts of interest regarding the publication of this paper.

\section{References}

Balachandra, R., \& John, H. F. (1997). Factors for Success in R\&D Projects and New Product Development. IEEE Transactions on Engineering Management, 44, 276-287. https://doi.org/10.1109/17.618169

Bublitz, B., \& Ettredge, M. (1989). The Information in Discretionary Outlays: Advertising, Research and Development. The Accounting Review, 64, 108-124.

Chan, L. K. C., Lakonishok, J., \& Sougiannis, T. (2001). The Stock Market Valuation of Research and Development Expenditures. The Journal of Finance, 6, 2431-2456. https://doi.org/10.1111/0022-1082.00411

Cho, S., \& Chung, J. (2001). The Effect of R\&D Expenditures on Subsequent Earnings. Korean Management Review, 30, 289-315.

Daniel, K. D., \& Titman, S. (2001). Market Reactions to Tangible and Intangible Information. Working Paper, Northwestern University. https://doi.org/10.2139/ssrn.274204

Eberhart, A. C., Maxwell, W. F., \& Siddique, A. R. (2004). An Examination of Long-Term Abnormal Stock Returns and Operating Performance Following R\&D Increases. The Journal of Finance, 59, 623-650. https://doi.org/10.1111/j.1540-6261.2004.00644.x

Folta, T. B., \& O’Brien, J. P. (2004). Entry in the Presence of Dueling Options. Strategic Management Journal, 25, 121-138. https://doi.org/10.1002/smj.368

Grant, R. M. (1984). Mutinationality and Performance among British Manufacturing Companies. Journal of International Business Studies, 18, 79-89. https://doi.org/10.1057/palgrave.jibs.8490413

Green, J. R., \& Scotchmer, S. (1995). On the Division of Profit in Sequential Innovation. Rand Journal of Economics, 26, 20-33. https://doi.org/10.2307/2556033

Grilches, Z., \& Mairesse, S. (1984). Productivity and R\&D at the Firm Level. In $R \& D, P a-$ tents, and Productivity (pp. 339-374). University of Chicago Press.

Hall, B. H. (1996). The Manufacturing Sector Masterfile: 1959-1987. NBER Working Paper No. 3366, National Bureau of Economic Research. 
Hall, B. H. (2000). Innovation and Market Value. In Productivity, Innovation, and Economic Performance (pp. 177-198). Cambridge University Press. https://doi.org/10.3386/w6984

Han, B. H., \& Manry, D. (2004). The Value-Relevance of R\&D and Advertising Expenditures: Evidence from Korea. The International Journal of Accounting, 39, 155-173. https://doi.org/10.1016/j.intacc.2004.02.002

Jo, S. P., \& Jung, J. Y. (2001). Analysis of the Effect on Corporate Performance of R\&D Expenditure in the Long Term. Research of Management, 30, 289-312.

Lanjouw, J. O., \& Shankerman, M. (2001). Characteristics of Patent Litigation: A Window on Competition. Rand Journal of Economics, 32, 129-151. https://doi.org/10.2307/2696401

Lev, B., \& Sougiannis, T. (1996). The Capitalization, Amortization, and Value-Relevance of R\&D. Journal of Accounting and Economics, 21, 107-138. https://doi.org/10.1016/0165-4101(95)00410-6

Namara, P. M., \& Fuller, C. B. (2007). Shareholder Returns and the Exploration-Exploitation Dilemma: R\&D Announcements by Biotechnology Firms. Research Policy, 36, 548-565. https://doi.org/10.1016/j.respol.2007.02.012

NIST (2019). Definition of Manufacturing-Related $R \& D$. https://www.nist.gov/tpo/definition-manufacturing-related-rd

Oriani, R., \& Sobrero, M. (2008). Uncertainty and the Market Valuation of R\&D within a Real Options Logic. Strategic Management Journal, 29, 343-361. https://doi.org/10.1002/smj.664

Sougiannis, T. (1994). The Accounting Based Valuation of Corporate R\&D. The Accounting Review, 69, 44-68.

Trigeorgis, L. (1996). Real Options: Managerial Flexibility and Strategy in Resource Allocation. MIT Press. 